\title{
Fragility Curves of Existing RC Buildings Based on Specific Structural Performance Levels
}

\author{
Marco Vona \\ School of Engineering, University of Basilicata, Potenza, Italy \\ Email: marco.vona@unibas.it
}

Received 26 March 2014; revised 26 April 2014; accepted 3 May 2014

Copyright (C) 2014 by author and Scientific Research Publishing Inc.

This work is licensed under the Creative Commons Attribution International License (CC BY).

http://creativecommons.org/licenses/by/4.0/

(c) (i) Open Access

\section{Abstract}

In seismic risk mitigation policies, fragility functions of existing buildings play a fundamental role. In this paper, a procedure to develop analytical fragility curves for Moment Resisting Frame Reinforced Concrete buildings is presented. The design of the selected building typologies was performed according to the codes at the time of construction using force-based methods and the state of the practice at the time of construction. A total of 216 building classes were defined, considering different ages, number of storeys, infill panels, plan dimensions, beam stiffness, and concrete strength. The investigated buildings can be considered low-engineered buildings, using no seismic codes or old seismic codes. The seismic capacity of the selected models representing the existing $\mathrm{RC}$ buildings has been evaluated through non-linear dynamic simulations. Seismic response has been analyzed, considering various peak and integral intensity measures and various response parameters, such as ductility demands and Interstorey Drift Ratio (IDR). A new relationship among structural performance, damage levels and interstorey drift ratios for each studied type is introduced, which is calibrated using the damage levels described in EMS98. It is important to highlight that in this study, different thresholds of IDR have been associated with different typologies, considering their different ductility member levels after their different structural responses. Fragility Curves (FCs) for the studied structural types are set up, developed and discussed.

\section{Keywords}

Existing RC Buildings, Building Damage Criteria, Fragility Curves, Structural Performance-Damage Levels Relationship

\section{Introduction}

Recent European earthquakes (e.g., Southern Italy 1980, Turkey 1999, L’Aquila 2009, Emilia plan 2012) have 
shown that structural performance of Reinforced Concrete (RC) buildings (in particular Moment Resistant Frame, MRF) always play crucial roles in terms of earthquake losses and urban resilience. Mainly due to the high vulnerability of the building stock, the resilience of the communities has been generally non-existent [1]. Framed RC structures are commonly found in many countries. They represent approximately $75 \%$ of the building stock in Turkey, approximately 60\% in Colombia, and over 30\% in Greece [2]. Moreover, in several past studies [3]-[6], the significant presence of RC MRF buildings in the Italian building stock has been noted. Consequently, in Italy and other Mediterranean earthquake-prone countries, the seismic performance of the building stock needs to be investigated.

Much works have already been done regarding understanding seismic risk and its mitigation [3]-[9], to allow simple and optimised rules for practical planning (support to decision maker) and design to be defined. Simple, fast, available, and economic retrofitting strategies should be defined and integrated in mitigation policies for non-seismic buildings. In this way, it is also possible to increase the resilience of cities in a short time after earthquakes (for example, as reported in the following). Tools specifically defined for emergency management and seismic risk mitigation policies must be defined. Examples of these tools are the Vulnerability Index and Fragility Curves (FCs) for building typologies, based on numerical analyses, to study the vulnerability and possible retrofitting.

Generally, these methods should be applied using a significant amount of data related to their characterisation, which can be obtained by historic failures, expert evaluation [10], and field survey or investigation [11]-[13]. It is the opinion of the author that the derivation of FCs from post-earthquake or expertise data cannot be sufficient for the realisation of a reliable risk assessment tool. In fact, even a validation for a similar area with surveyed damage may not be sufficient to extend the obtained results. Thus, on the basis of this comparison, the provided results might be grossly misleading. On the other hand, the comparison with past events may not be useful to the forecast for the future. On the contrary, this approach must be supplemented by numerical analyses.

Generally, a newly proposed method should be capable, on the one hand, to ensure sufficient reliability, and the preparation of seismic scenarios should not be too costly; on the other hand, the newly proposed method should ensure a realistic prevision of the structural performance of the studied buildings to define accurate, large-scale retrofitting policies.

Due to the importance of the topic, a considerable number of studies were funded, developed and published in the last years in order to define FCs (e.g., [14]-[27]).

Nevertheless, the complexity of the problem requires further enhancements in order to define effective tools for prevention and mitigation of the seismic risk (for example, in [28] and [29]).

These studies are based on different analysis methods and procedures. They are generally refereed to several typologies of RC structures built in a single country. These studies have been generally carried out on the basis of push-over analysis. This method is generally less accurate than Non Linear Dynamic Analyses (NDLAs). The results should be validated through more realistic NDLAs.

In the present work, a significant number of building types are selected and characterised and are analysed through accurate NDLAs. Moreover, the structural response of the buildings is expected to be characterised for significant uncertainties. As widely reported in previous studies ([30] [31]), the variability (randomness) of the seismic action plays a fundamental role in the variability of the structural response. Significant efforts have been devoted to considering these fundamental topics ([7] [9] [30]).

In order to evaluate the seismic vulnerability of MRF RC structures, a specific performance-based assessment framework is needed. An interesting approach is presented by the PEER Center [15]. This approach was developed based on data from USA buildings and hazards, so it cannot be applied to other seismic regions or other parts of the world where building design practices are generally significantly different. This is particularly the case for Mediterranean RC buildings and their seismic performance assessments with regard particularly to hazard analysis, response and damage analyses, and loss analysis. It is clear that the proposed performance assessment procedure in this study could be used to improve the seismic risk analysis in Mediterranean areas.

Generally, a good procedure to define the expected damage is a mechanics-based approach. On the basis of deformation demands, the result of the procedure should be physical damage to the structure. Damage levels could also be defined based on repair costs. In any case, generally these methods should be applicable only when using a significant amount of data related to their characterisation, which can be obtained by historic failures, expert evaluation [10] and field survey or investigation [11]-[13]. The derivation of FCs from post-earthquake or expertise data (e.g., empirical data) cannot be sufficient for the realisation of a reliable risk assessment 
tool. On the contrary, this approach must be supplemented by numerical analyses. The main reason for using accurate, analytical methods in the derivation of FCs is the lack of post-earthquake damage data.

Concerning RC MRF structures, in ASCE 41-06 [32], a quantitative procedure for performance levels is provided, defining some deterministic interstorey drift ratio limits for different performance levels. Although these approximate limits can seem fairly reasonable, it is clear that for each building type and each territorial application, the specific limits should be defined.

Thus, the fundamental step of the present work, in order to achieve the proposed objective, is the correct definition of the relationship between damage level and damage status defined through accurate non-linear analyses. This objective has a fundamental role in the assessment of the seismic capacity of existing construction, in post-earthquake emergency management and in experimental activity (numerical or in the laboratory). From qualitative damage level definitions (for example, EMS98 [33]), a quantitative limit state should be derived by considering the performance response of the structures. Each damage level should be quantitatively established through limit values of local demand parameters on structural members. Then, the correlation between local and global failure can be established. The proposed method uses global performance indicators to determine whether the results of numerical analysis can be considered as conforming to a specified damage level.

The present work would be an additional contribution along the complex path to seismic risk reduction through the improvement of the seismic vulnerability assessment of RC MRF buildings.

\section{General Overview of the Methodology}

The results reported and discussed in this work are the consequent evolution of previous work [9] [30]. Nevertheless, for a better understanding, some parts of the seismic performance assessment method are briefly reported in this paper, while the flowchart of the methodology is shown in Figure 1.

First, a wide and complex investigation was developed in order to understand the peculiarity of the seismic performance of existing MRF RC structures. MRF RC structures were widely characterised. In the current study, a procedure for the performance assessment of typical dwelling buildings was established. Buildings designed and constructed before and after 1971 were studied in order to define building typologies that are considered representative of those "as built" in Italy and in Mediterranean countries, with building stock very similar to the Italian one.

Two main types of only gravity-load designed MRF RC structures were considered: the first type can be considered low engineered buildings and the second one can be considered to be designed with old codes in Southern Europe. These characterisations can be considered consistent with those reported in Kappos and Panagopoulos [24]. In particular, old code types can be considered consistent with low code and Moderate code in Kappos and Panagopoulos [24].

To this aim, different design codes in force in 1939-1981 were considered. In fact, after this year, the building can be considered as seismically designed with a more modern code. Moreover, the 1984 Italian code strongly

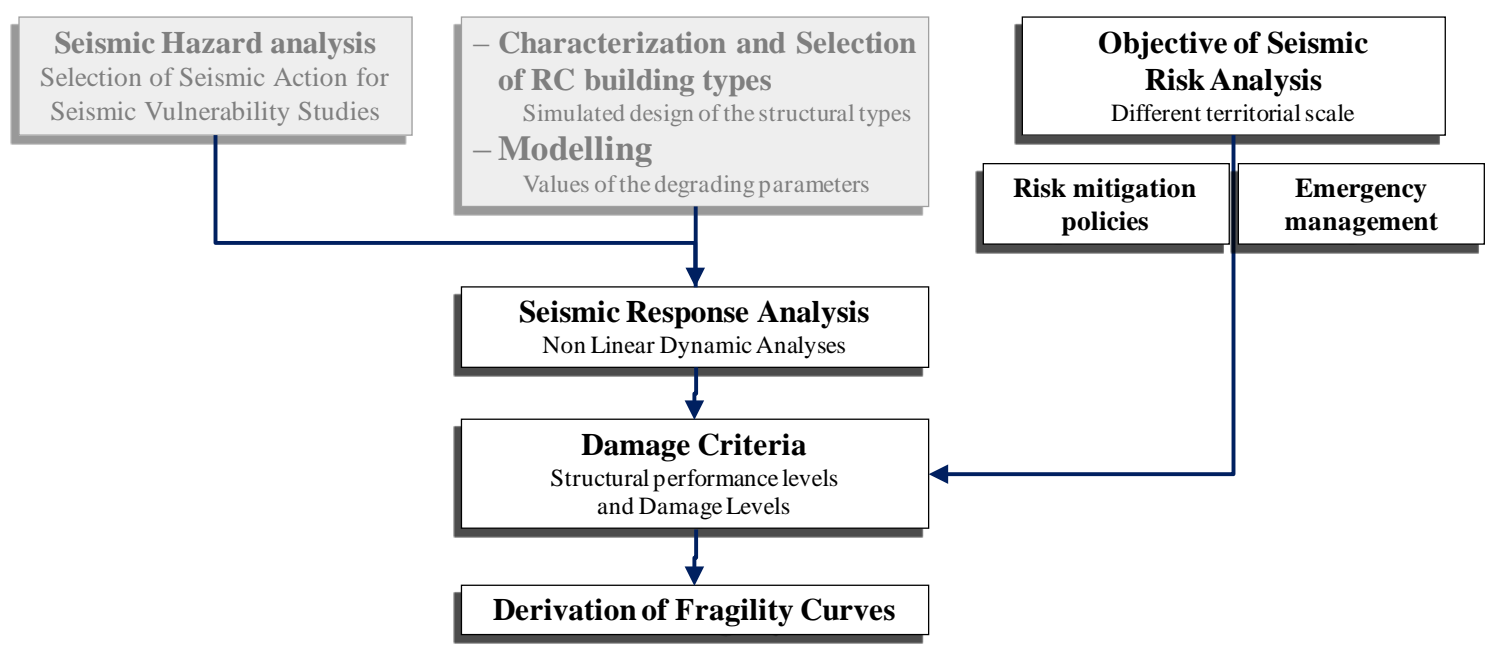

Figure 1. Flowchart of the proposed method: In grey part of procedure widely reported in [9] [30]. 
updated the Italian code; in the updated code, significant new seismic design prescriptions were provided.

Much care has been devoted to defining material properties, accurate knowledge of structural elements characteristics (location and details of reinforcement) and deterioration conditions [9] [34].

As for the low engineered structures, low strength concrete and smooth steel bars were typically used, while after 1971, higher strength concrete and deformed steel have been increasingly used. The first types are called Pre-Code RC buildings, and they can be considered low-engineered buildings. The second ones (1972-1984) are called Old-Code RC buildings.

These existing RC buildings generally showed a non-ductile behaviour (for example, Masi and Vona [35], Ditomasso et al. [36]). Moreover, it seems interesting to highlight that often the structural performance of buildings designed both with old seismic code and without anti-seismic criteria do not seem different, as already shown in previous work [36] [37]. This similarity can be ascribed to the use of old seismic design codes. On the other hand, it is worth noting that the seismic damage is not much different (as shown by surveyed damage [36]). At this point, it is to be noted that when considering the entire Italian residential building stock (ISTAT, [38]), the investigated types are a significant part, representing approximately $16 \%$ of the total number of residential buildings and more than $63 \%$ of RC residential buildings.

RC types are characterised by frames only in one direction (longitudinal, longer building direction), as they are typically designed for gravity load (as well as weakness, seismically designed buildings or designed with old seismic code). In the transversal direction, only exterior frames and internal frames guaranteed by the contribution of the floor slabs (No Beam, NB) have been considered. Due to this characteristic, the transversal direction can be considered the weak direction. As the typical characteristics of the Italian and European residential buildings, the presence of masonry infill walls has been considered between the columns of the two exterior frames. Different degrees of stiffness have been considered for exterior transversal frames due to beams (Flexible Beam, FB, within the floor slab thickness, and Rigid Beam, RB, emergent beams). Regarding plan dimension, two different cases were considered: small and large plan area. Finally, in order to investigate how the number of storeys in a building affects its behaviour, three cases were analysed: low, mid and high-rise types (respectively, 2, 4 and 8 storeys). Figure 2 shows all the structural types considered in the paper.

On the basis of different structural details (Pre-Code or Old-Code) and materials, degrading parameters have been defined. The material properties and adopted values of the degrading parameters are documented both in Masi and Vona [9] and Borzi et al. [7]. Finally, a total of 216 building classes have been considered. Seismic performance assessment has been investigated through NLDAs. Certainly, this is the most accurate method to investigate the structural performance of RC MRF buildings, particularly existing buildings designed with old seismic code or without anti-seismic criteria. In fact, NLDA is able to take into account the real characteristics of the seismic input and the evolution of the structural response (cyclic degrading behaviour and dissipation capacities). A three-parameter hysteretic model [39] [40] has been used. The values of these parameters have been defined on the basis of the various experimental work (see Masi and Vona [9]).

Several studies (e.g., [14] [16] [41] [42]) in recent years have highlighted the crucial role of seismic input for a correct evaluation of structure response. Thus, accelerograms were selected using the procedure defined in
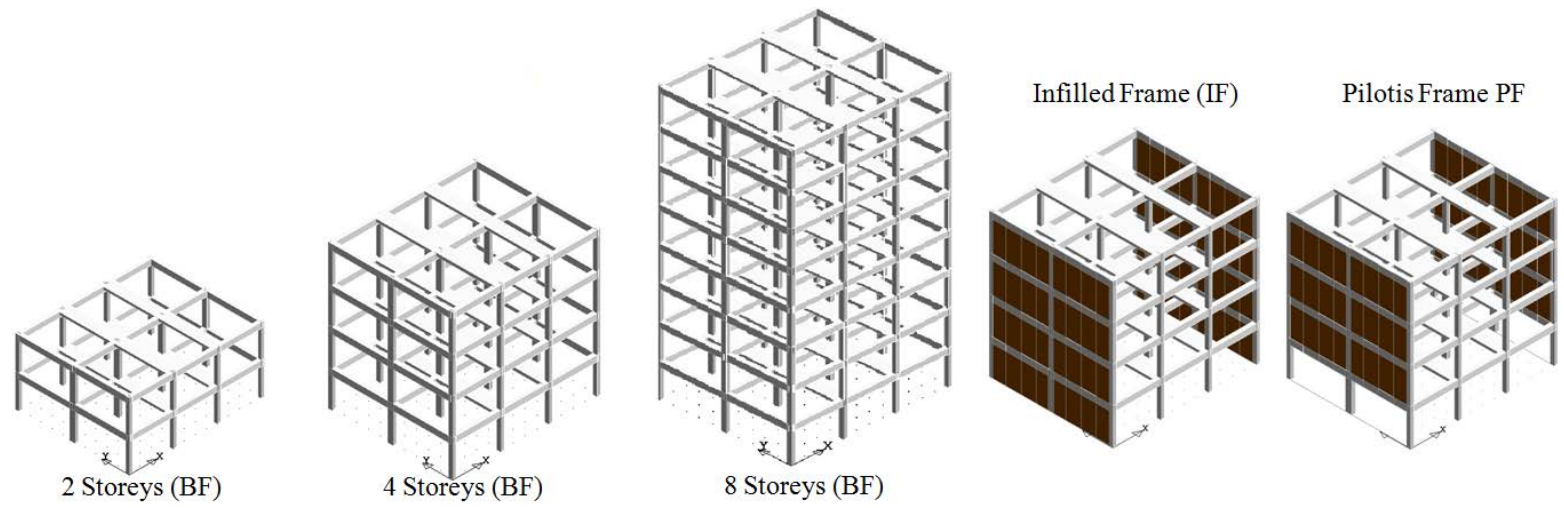

Figure 2. Number of the storey (on the left) and infill distributions (on the right) of the building types considered in the study. 
Masi et al. [30]. In this way, it is the opinion of the author that accelerograms of real earthquakes are the best choice for vulnerability studies on existing RC buildings. The recorded accelerograms contained in the ESMDatabase [43] have been chosen. For the selection, the following peak and integral has been considered. The $I_{H}$ values of the 50 accelerograms encompass the range of $0.09-2.34 \mathrm{~m}$, while the PGA values in the 0.05 $0.50 \mathrm{~s}$ range have been considered. Further details regarding all 50 selected accelerograms are reported in Masi and Vona [9]. The earthquake motions have been applied in both main directions in plan.

As reported in previous studies ([9] [30]), the Housner Intensity $I_{H}$ can be considered a good seismic intensity measure. Different intensity types are more or less appropriate in different situations. Results reported in previous studies ([9] [30]), show that the Housner Intensity $I_{H}$ can be used in this study as the best seismic intensity measure. Nevertheless, in the next works, FCs could be defined using PGA or other seismic intensity parameters (PGV, Arias Intensity, etc.). Moreover, as was already demonstrated in Masi et al. [9], the integral measurements of seismic intensity are often more effective than peak or spectral parameters to represent the damage potential of ground motion. It needs to be highlighted that elastic spectral ordinates (corresponding to the fundamental period of the building) are not able to take into account progressive structural stiffness degradation, change of modal characteristics and period elongation of the structure (as those considered in this studies) for increasing values of external action. More discussion is reported in Masi et al. [9], as motivation for the use of the Housner Intensity (an integral ground motion parameter) for the development of FCs as opposed to the use of other parameters such as peak ground acceleration or peak ground velocity that cannot be easily linked to the EMS intensity scale. In fact, in Chiauzzi et al. [5], a reference to $I_{H}$ is made, considering that a relationship to convert $I_{H}$ into EMS98 [33] intensity has been defined.

This relationship is useful in large scale loss scenarios (e.g., Puglia et al. [8]), such as those prepared using classical tools (for example, based on Damage Probability Matrices [3]). Nonetheless, in the future elaboration, FCs could be defined considering each of the seismic parameters in the previous reported section.

\section{Results}

A previous work [9] widely investigated seismic response. High coefficients of correlation between drift and ductility in structural elements were found. Consequently, the results were discussed considering drift values only.

As in previous work, the performance levels have been analysed considering the Interstorey Drift Ratio (IDR, $\mathrm{drift} / h$ where $h$ is interstorey height) as the only response parameter. IDR can be easily correlated with structural and non-structural damage, and it is also consistent with the effects of the observed strong earthquakes [21] [25]-[27] [41]. Then, the results of NLDAs have been investigated in order to define a new relationship among Seismic Performance (SP), Damage Levels (DL) and Interstorey Drift (IDR).

Moreover, according to the NDLAs results, different damage levels have been defined at different IDR for each type. These differences can be due to different ages (e.g., old or no seismic standard design), number of storeys, infill panel distribution, material properties, and reinforcement details, among others.

The results of NLDAs have been reported and discussed, investigating the relationship between Seismic Performance (SP), Damage Levels (DL) and Interstorey Drift (IDR) for each of the studied types (Figure 3).

In the present work, a new key to evaluate the performance levels of the analysed structures is considered in order to develop a new set of FCs. In this way, it is now well established that the IDR is considered a good indicator of damage for RC buildings. Moreover, it is well correlated with structural and non-structural damage [16] [44]. This is also consistent with the effects of the observed strong earthquakes [21] [25]-[27] [41].

When overcoming and integrating these simple approaches, it is important to note that for each type of building, different levels of damage can be obtained at different levels of drift. These differences can be due to, for example, different ages (e.g., old or no seismic standard design), number of storeys, infill panel distribution, material property, and reinforcement details.

Concerning the adopted parameters used to classify types and build FCs, the results reported in a previous study [9] show that some parameters are less important in performance levels when compared to others. Thus, the results of the investigated types have been discussed, considering the age, building height, and infill distribution (BF, IF, PF); 18 types have been considered. In the following, NDLA results are reported and summarised to achieve a useful interpretation to define the Damage Levels-Interstorey Drift Ratio relationship. Collapse under each ground motion is defined directly from NDLAs in terms of excessive lateral displacement (instability) 


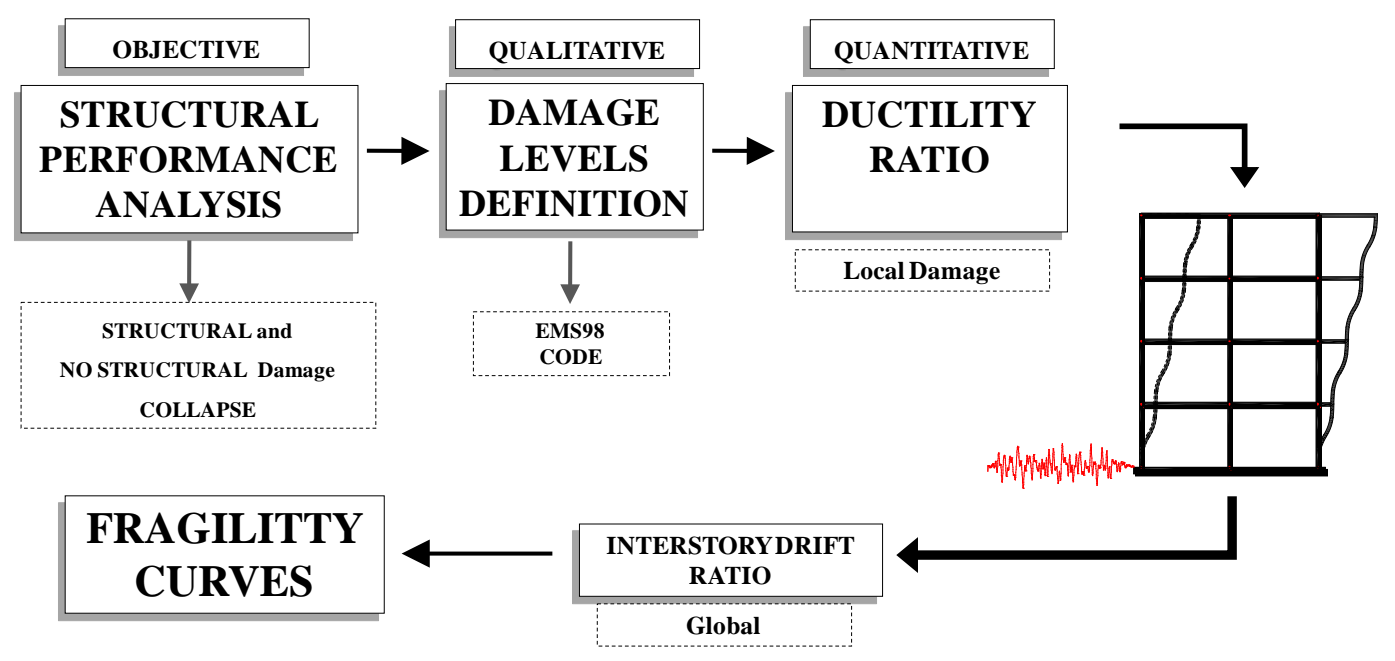

Figure 3. Framework to define Interstorey Drift Ratio levels for each type.

or is evaluated through section yield levels.

- Elaborations of the results have been carried out in order to investigate:

- Differences between types in terms of maximum IDR versus seismic intensity (SI).

- Localisation of Ductility Ratio in structural members (beams and columns).

The box and whisker plots, also called box plots, reported in Figure 4 and Figure 5 represent the statistical parameters inferred for maximum drift/h $I D R_{\max }$ for each considered type at different seismic intensities. Each box plot encloses $50 \%$ of the data with the median value displayed as a thin line (within the box), and the top and the bottom of the box mark the limits of $25 \%$ and $75 \%$ of the population, respectively. The whiskers represent the maximum and minimum values of the population. These plots are a convenient way to graphically depict groups of numerical datasets. Moreover, in box plots, observations considered outliers due to numerical collapse have also been identified. These values have been deleted in the reported figures. Thus, for higher values of seismic intensity (generally only $I_{H} \geq 1.5$ ), drift $/ \mathrm{h}$ values analysed and reported in the figures could be underestimated.

Significant differences in terms of $I D R_{\max }$-SI between the considered types can be noted. Globally, more remarkable differences are due to infill panels and their distribution, but it needs to be highlighted that significant differences have been found due to the different numbers of storeys. From the analysis of Figure 4 and Figure 5, it is possible to infer that generally greater displacements are obtained for BF and PF types. For IF types (independent of the number of storeys in the buildings), the absolute $I D R_{\max }$ values are smaller, and the dispersion of the data is much lower. Moreover, the growth trend of the $I D R_{\max }$ is significantly smaller.

Comparable trends can be seen in Old-Code (Figure 4) and Pre-Code types (Figure 5) in relation to the qualitative role of infill and height. Generally, IDR values are higher for Pre-Code types, and the negative role of PF types is more marked.

In the following (Figures 6-8), the results and discussion are relative to Old-Code types, but it is important to consider that similar trends have also been observed for Pre-Code types regarding the role of infill and building height.

Analysing the data shown in Figures 6-8, two fundamental results are evident. First, the higher maximum Ductility Ratio (DRmax) values are generally obtained at the first story. Second, higher values are achieved for columns (DRC) rather than beams (DRB). It is interesting to note that for PF types (independent of the number of storeys in the buildings), the DRCmax at first story is always higher than other storeys.

In this work, the following parameters have been also considered in order to achieve the goals reported above:

- DBmax: maximum required Ductility in each Beam.

- DCmax: maximum required Ductility Ratio in each Column.

From the above analyses and comments, the Damage Levels-IDR relationship must be considered for each type. Thus, using the presented results, it is possible to define the fundamental Structural Performance levels (based on Ductility Ratio)—Damage Levels_IDR relationship to build FCs. 


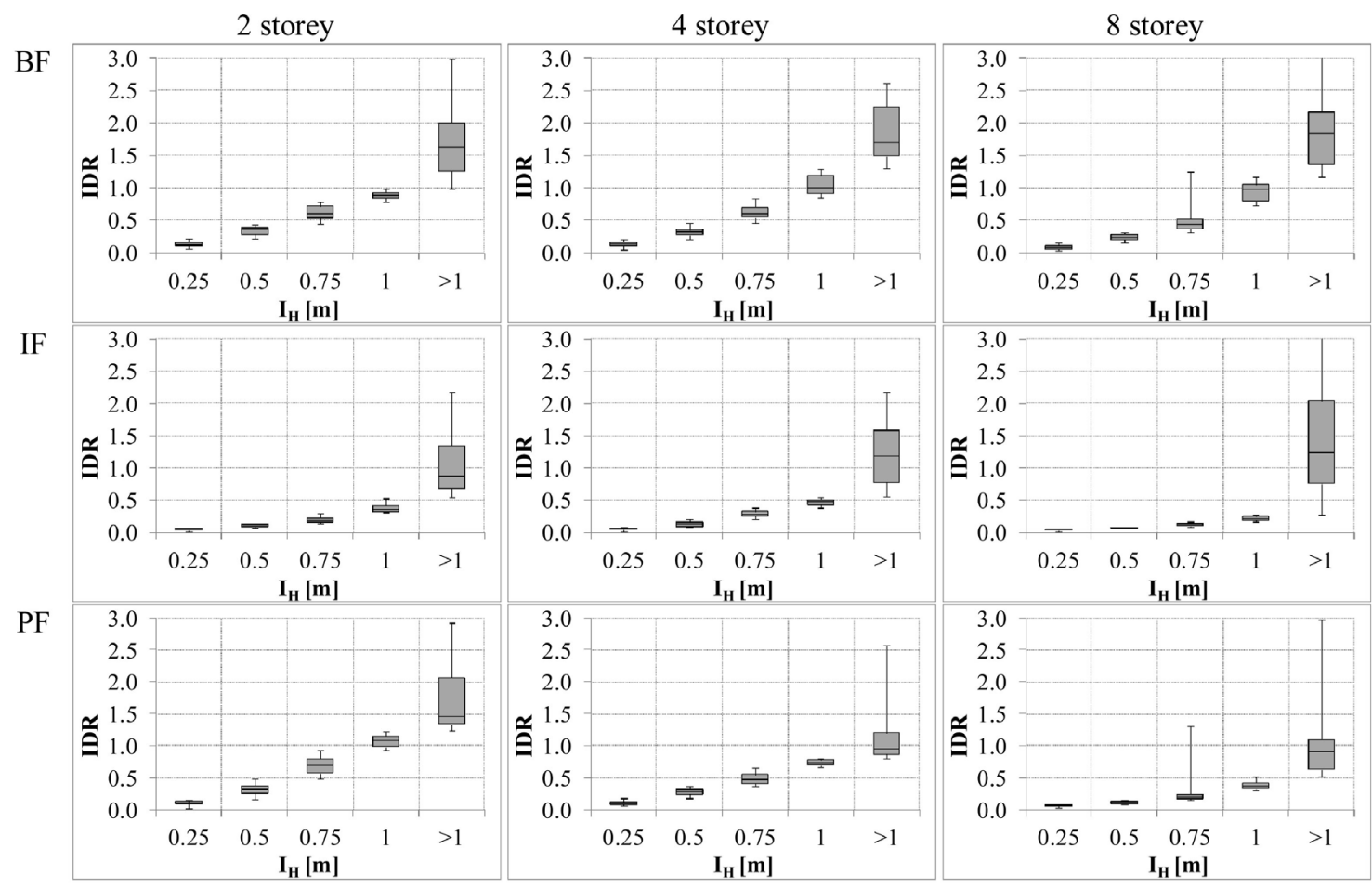

Figure 4. Old-Code types. Each box encloses $50 \%$ of the data with the median value of the maximum IDR displayed as a thin line, within the box; the top and the bottom of the box mark the limits of $25 \%$ and $75 \%$, respectively of the population; the whiskers represent, respectively the maximum and minimum values of the population.

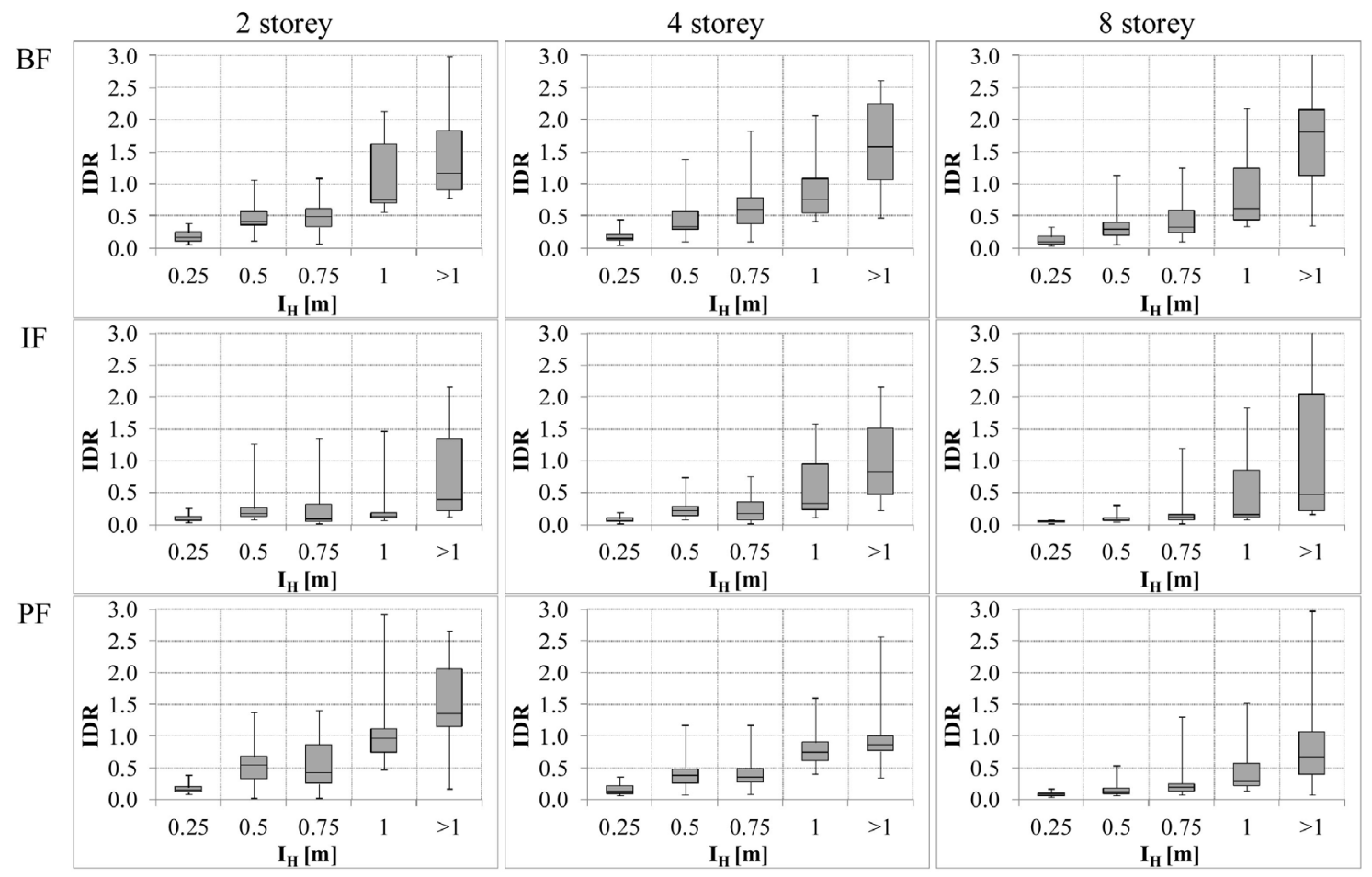

Figure 5. Pre-Code types. Each box encloses $50 \%$ of the data with the median value of the maximum IDR displayed as a thin line within the box; the top and the bottom of the box mark the limits of $25 \%$ and $75 \%$, respectively of the population; the whiskers represent, respectively the maximum and minimum values of the population. 
IF

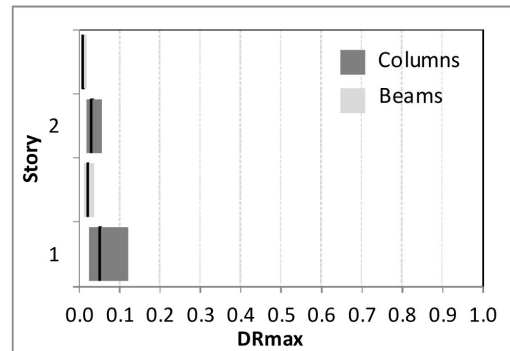

$\mathrm{BF}$

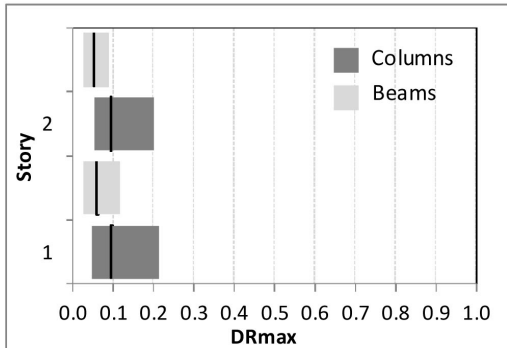

$\mathrm{PF}$

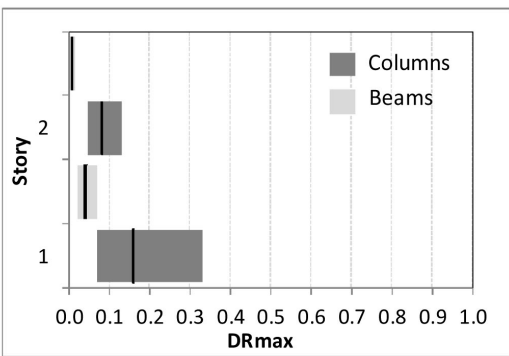

Figure 6. BF Old-Code 2 storey type. Each box encloses $50 \%$ of the data with the median value of the DRCmax and DRTmax (thin line within the box). The top and the bottom of the box mark the limits of $25 \%$ and $75 \%$, respectively of the population.

IF

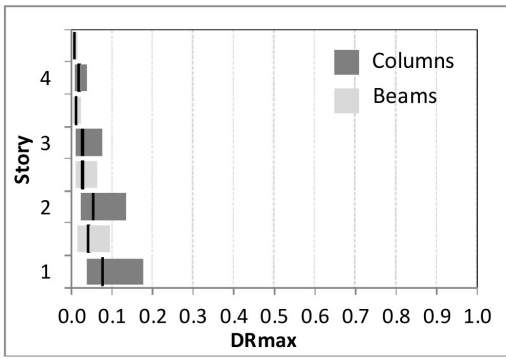

$\mathrm{BF}$

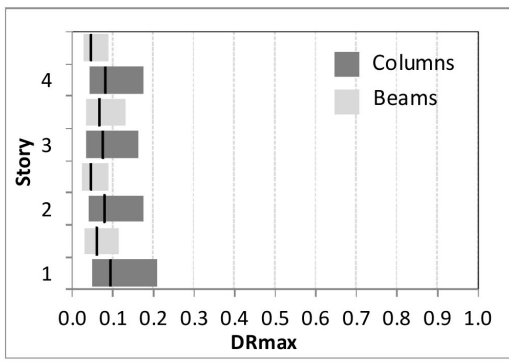

$\mathrm{PF}$

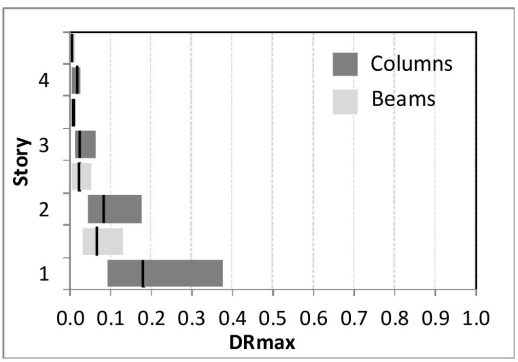

Figure 7. BF Old-Code 4 storey type. Each box encloses $50 \%$ of the data with the median value of the DRCmax and DRTmax (thin line within the box). The top and the bottom of the box mark the limits of $25 \%$ and $75 \%$, respectively of the population.

IF

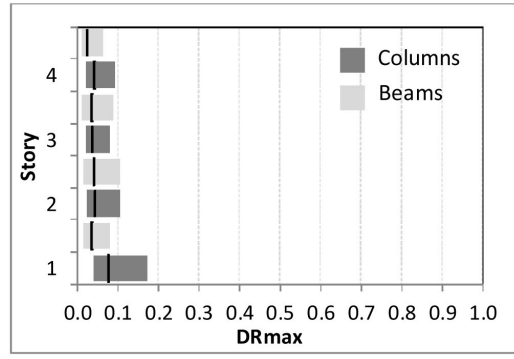

$\mathrm{BF}$

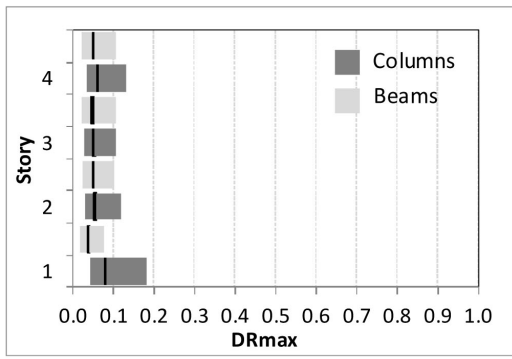

PF

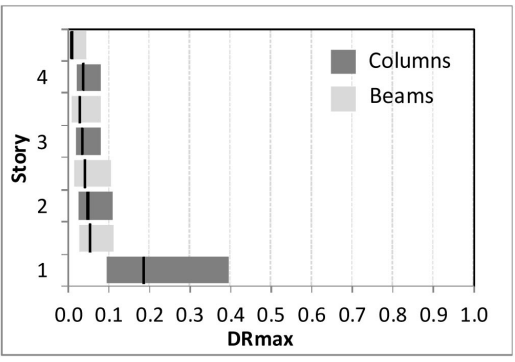

Figure 8. BF Old-Code 8 storey type. Each box encloses $50 \%$ of the data with the median value of the DRCmax and DRTmax (thin line within the box). The top and the bottom of the box mark the limits of $25 \%$ and $75 \%$, respectively of the population.

\subsection{Structural Performance Levels and Damage Levels}

In order to achieve the main goal, damage levels described in EMS98 [33] have been considered to define structural performance levels (qualitative damage description, Figure 3). In EMS98 [33], the damage levels ranged from DL $=1$ (DL1, non-structural damage) to DL $=5$ (DL5, collapse). Global performance parameters for a given damage level have been obtained from an update of the damage classification. Different correlations among structural performance levels, damage levels and IDR can be searched. Then, at each condition of lateral deformation, it should associate a limit state reflecting a section yield level (a specified limit for the ductility demand of columns and/or beams).

First, relationships between the IDR and other parameters governing the seismic structural performance levels must be defined. In order to simplify the quantification, it is not straightforward to formulate these relationships 
as a univocal function. Moreover, the peculiarity of RC MRF buildings treated in this work makes it necessary to build a specific damage levels-interstorey drift relationship. This relationship (based on Ductility Ratio obtained from NDLAs) could be mainly defined for each of the different building typologies (BF, IF, PF), different ages and storey numbers. Thus, the damage levels described in EMS98 [33] have been considered to define structural performance levels. In EMS 98, the damage levels range from DL = 1 (DL1, non-structural damage) to $\mathrm{DL}=5$ (DL5, collapse).

Then, different damage states have been defined, considering the IDR as representative of the structural response. However, it is important to highlight that in this study, different thresholds of IDR have been associated with different typologies, considering their different ductility member levels after their different structural responses. This approach seems to be more appropriate with reference to the seismic capacity of RC buildings considered in this study.

With regard to DL1, this damage level is defined in EMS98 [33] as: "Negligible to slight damage (only No-Structural Damage)". For RC buildings, DL1 is defined as: "fine cracks in plaster over frame members or in walls at the base, fine cracks in partition and infills".

DL1 is correlated with global behaviour described as only light damage to the building, with structural elements prevented from significant yielding and retaining their strength and stiffness properties. In terms of structural members, DL1 is assumed, considering that the system remains essentially elastic for this damage level. It should be remarked that in this work, only inter-storey, drift-sensitive, non-structural components have been considered. DL1 has been defined considering an IDR limitation to $0.1 \%$.

In EMS98, the DL = 2 (DL2) and DL = 3 (DL3) damage levels are defined, respectively, as:

- "Cracks in columns and beams of frames and in structural walls. Cracks in partition and infill walls; fall of brittle cladding and plaster. Falling mortar from the joints of wall panels".

- "Cracks in columns and beam column joints of frames at the base and at joints of coupled walls. Spalling of concrete cover, buckling of reinforced rods. Large cracks in partition and infill walls, failure of individual infill panels".

This difference is a fundamental step in the use of the FCs to build seismic scenarios. DL2 and DL3 cannot be considered to correspond to a single performance level. A fundamental step in the proposed procedures is the quantitative definition of DL2 and DL3. In fact, in this way it is possible to differentiate unusable buildings on long periods (DL3) from those usable after simpler retrofitting or reparation (DL2).

DL4 has been considered when the structure has suffered at least heavy damage, with low residual lateral strength and stiffness. Damage Level 4 is obviously considered hardly, or more often, not repairable. The next step in the procedure is differentiating quantitatively among DL2, DL3 and DL4 in terms of structural performance levels.

The references could be some codes. Various alternatives are possible, and this work has chosen to follow the instructions contained in some codes, such as NTC 2008 [45], EC8 [46]. In particular, for columns and beams considered as primary components, the deformation for the SD performance level shall not exceed three quarters (75\%) of the ultimate value. Instead, if the DL must be considered to minimise cost and repair time for immediate occupancy, for columns and beams considered as primary components, the deformation for the DL shall not exceed $10 \%-25 \%$ of the ultimate value. In addition, the damage levels 4 and 5 defined in EMS98 [33] have been considered as the only damage levels in order to define FCs (DL4 in the following). In the following, a singularity of the equivalent stiffness matrix (that represents an unstable structure) has also been considered as representative of the collapse of the building (DL4). These incomplete analyses result in very large displacements values.

From the above analyses and statements, for each type, the Structural Performance levels (based on Ductility Ratio)—Damage Levels—rift/h relationship has been defined.

The damage states have been defined considering the ductility ratio for only the columns at different yield levels. Damage levels are identified on the basis of the first column that achieves the defined damage state. Based on the above consideration, DL2, DL3 and DL4 have been defined in the following way (Table 1).

\subsection{Fragility Curves}

Generally, performance levels are defined from a given demand parameter or from a damage quantitative definition. In this study, as widely discussed in the previous section, a specific relationship between damage levels and 
Table 1. Damage criteria to define Structural Performance (beams and columns considered as primary components for DL2, DL3, DL4).

\begin{tabular}{|c|c|c|c|c|}
\hline EMS98 & Damage level & Performance & Reparability & Ductility Ratio \\
\hline $4(5)$ & $\begin{array}{l}\text { Heavy } \\
\text { (collapse } \\
\text { near collapse) }\end{array}$ & $\begin{array}{l}\text { For columns and beams considered as primary } \\
\text { components deformation exceeds three quarters (75\%) } \\
\text { of the ultimate value and at most one structural } \\
\text { elements exceed the ultimate value }\end{array}$ & $\begin{array}{l}\text { Hardly repairable } \\
\text { or more often } \\
\text { No repairable }\end{array}$ & $\begin{array}{l}1.00>\text { DRCmax }>0.75 \\
1.00>\text { DRBmax }>0.75\end{array}$ \\
\hline 3 & $\begin{array}{l}\text { Significant/ } \\
\text { Medium } \\
\text { Structural damage }\end{array}$ & $\begin{array}{l}\text { For columns and beams considered as primary } \\
\text { components the deformation not exceed three quarters } \\
(75 \%) \text { of the ultimate value }\end{array}$ & $\begin{array}{l}\text { Repairable } \\
\text { More expansive }\end{array}$ & $\begin{array}{l}\text { DRCmax } 0.25-0.75 \\
\text { DRBmax } 0.25-0.75\end{array}$ \\
\hline 2 & $\begin{array}{l}\text { Moderate/ } \\
\text { Low } \\
\text { Structural damage }\end{array}$ & $\begin{array}{l}\text { For columns and beams considered as primary components } \\
\text { the deformation not exceed } 25 \% \text { of the ultimate value }\end{array}$ & Easily repairable & $\begin{array}{l}\mathrm{DRCmax}<0.25 \\
\mathrm{DRBmax}<0.25\end{array}$ \\
\hline 1 & $\begin{array}{l}\text { Weak } \\
\text { No Structural } \\
\text { damage }\end{array}$ & $\begin{array}{c}\text { For columns and beams, the deformation not exceeds elastic } \\
\text { limit. Only inter-storey drift-sensitive non-structural } \\
\text { components are considered }\end{array}$ & Total & $\begin{array}{l}\text { DRCmax }<1 \\
\text { DRBmax }<1 \\
\text { IDR }<0.1 \%\end{array}$ \\
\hline 0 & None & -- & & -- \\
\hline
\end{tabular}

drift has been defined. FCs are a representation of the link between the probability of Damage Levels reached at a defined demand.

The developed FCs are "Cumulative Distribution Functions" (CDF) defined by the median of the seismic intensity measure, corresponding to the exceeding of a given damage level and the dispersion obtained from the standard deviation of the natural log, obtained from NDLAs. FCs have been built simply as $P\left[d_{S i} \mid I_{H}\right]$. This approach has been frequently used by researchers, and it is robust.

On the basis of the two-parameter log normal distribution function, the FC curve is defined in Equation (1):

$$
P\left[d_{S i} \mid I_{H}\right]=\Phi\left[\frac{1}{\beta_{d_{S i}}} \cdot \ln \left(\frac{I_{H}}{\mu_{d s}}\right)\right]
$$

where,

$\mu_{d s}$ is the median value of the Housner Intensity of the damage state $\left(d_{S i}\right)$;

$\beta_{d_{S i}}$ is the standard deviation of the natural logarithm of the Housner Intensity for the damage state;

$\Phi$ is the standard normal cumulative distribution function.

Concerning the parameters representative of the structural types, 18 FCs have been built. Different FCs have been defined, considering the building age and the role of infill distribution and building height.

The obtained FCs are reported in Figures 9-14 for the considered types.

The results show that the lower damage levels are obtained in IF types. The differences between Pre-Code and Old-Code building types have been investigated. It is clear that a significant difference between non structural damage and structural damage exists. This behaviour is particularly important for 4 and 8 storey types. Generally, it is obvious from the previous figures that the PF type is more vulnerable to damage than their corresponding IF and BF types at a given number of stories. The negative effects of Pilotis are more evident with regard to mid to high-rise buildings. Thanks to its stiffness, for Old-Code-2 storey IF type, the damage evolves quickly on higher levels. The results show that the damage levels are higher in Pre-Code PF types rather than in Old-Code types. Lower or negligible differences have been found in IF and BF types.

The fundamental role of infill panel distribution (causing irregularities in elevation) has been highlighted coherently with surveyed damage after recent earthquakes.

Considering the relationship to convert $I_{H}$ into EMS98 [33] intensity (see Chiauzzi et al. [5]), FCs can be used in large scale loss scenarios. Moreover, FCs can be defined on the basis of each of the seismic parameters, considering the seismic input selection. Thus, it is easy to compare different approaches to estimate the vulnerability of the buildings. 
IF

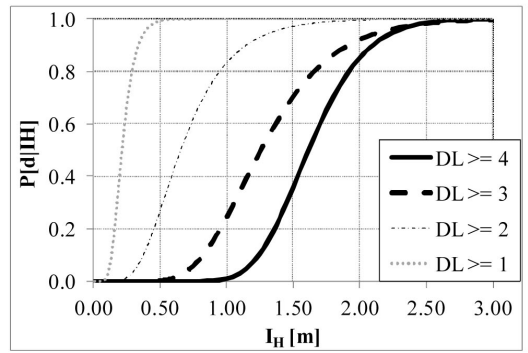

$\mathrm{BF}$

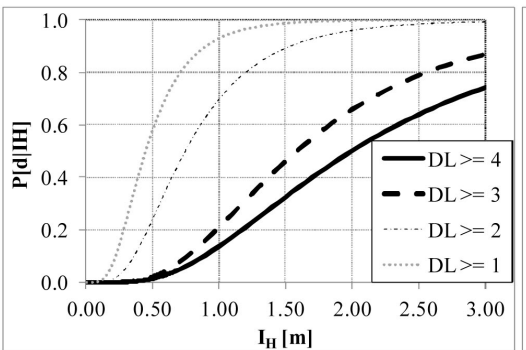

PF

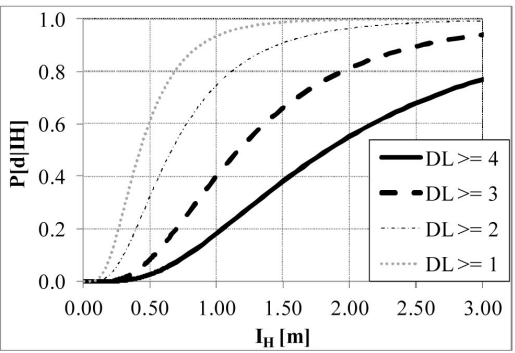

Figure 9. Fragility curves: Old-Code 2 storey IF, BF, PF.

IF

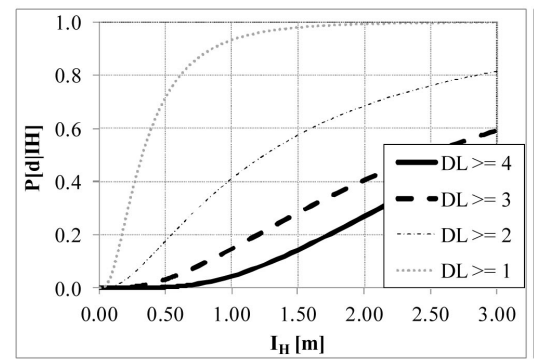

$\mathrm{BF}$

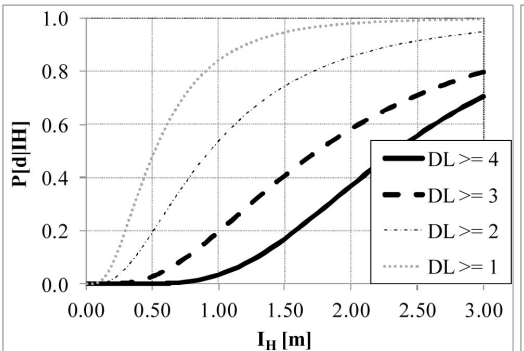

PF

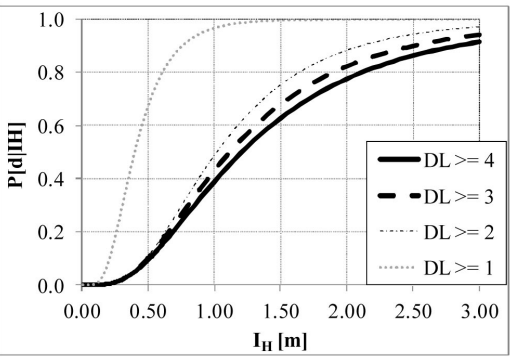

Figure 10. Fragility curves: Old-Code 4 storey IF, BF, PF.

IF

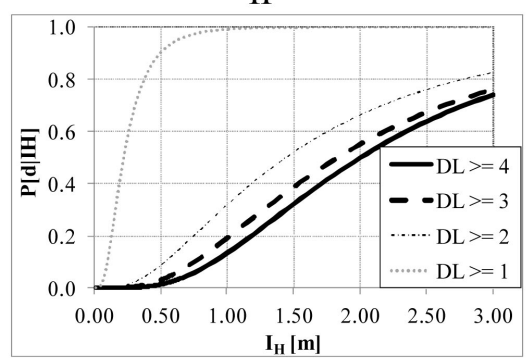

$\mathrm{BF}$

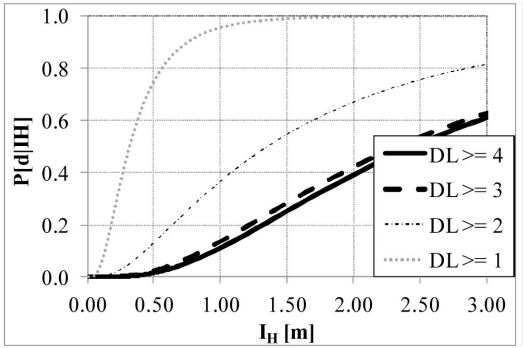

$\mathrm{PF}$

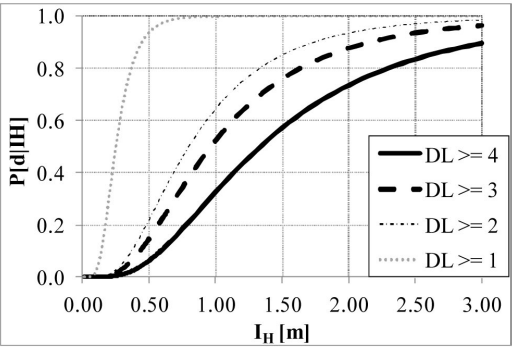

Figure 11. Fragility curves: Old-Code 8 storey IF, BF, PF.

\section{Conclusion and Remarks}

In this paper, a procedure to develop analytical FCs for MRF RC buildings is presented. In seismic risk mitigation policies, FCs must be defined considering also the different territorial scales that are studied. FCs must be defined considering also the repair/retrofitting costs. Therefore, FCs will be defined considering an economic point of view, which requires that the higher level of economic losses be adequately captured. Alternative performance definitions must be proposed to establish risk and cost-related losses.

In this paper, FCs are defined considering seismic risk mitigation policy needs at different territorial scales. The investigated buildings can be considered low engineered buildings, pre seismic code or old seismic code.

In literature, there are very interesting works on the seismic vulnerability of different typologies of buildings. Generally, FCs have been derived from post-earthquake or expertise data. Unfortunately, due to lack of data the provided, results might be grossly misleading. For this reason, this approach needs to be supplemented by numerical analyses.

Several other studies are based on numerical analyses. These studies have been often carried out on the basis of push-over analysis. This method is generally less accurate than Non Linear Dynamic Analyses (NDLAs) considered in the present work. On the basis of NDLAs, the specific limits have been defined for each building type analyzed. Specific relationships between damage level (qualitative) and damage status (quantitative) have been defined for each considered types. 

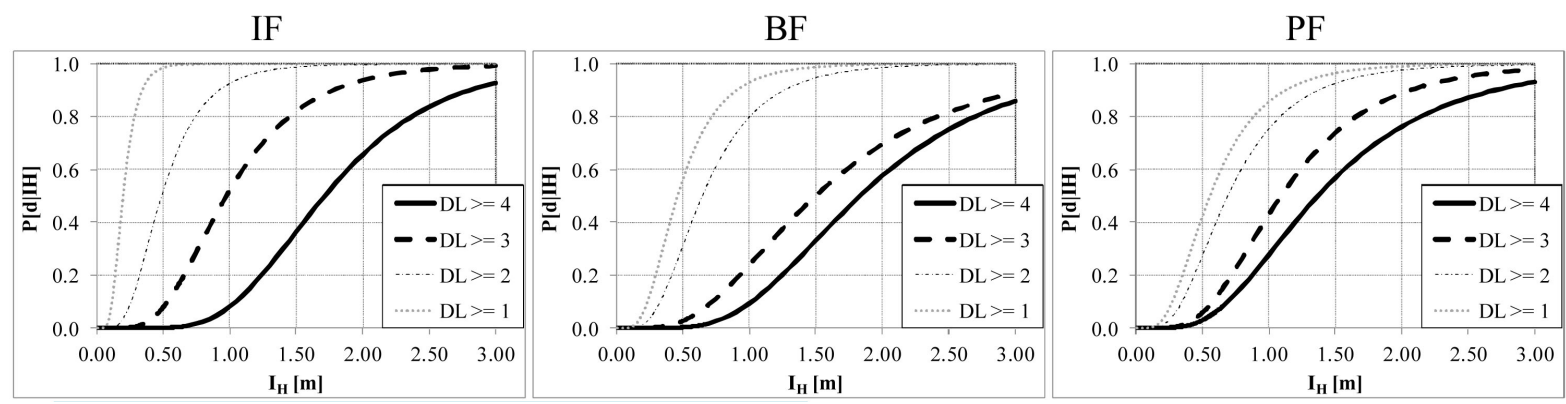

Figure 12. Fragility curves: Pre-Code 2 storey IF, BF, PF.
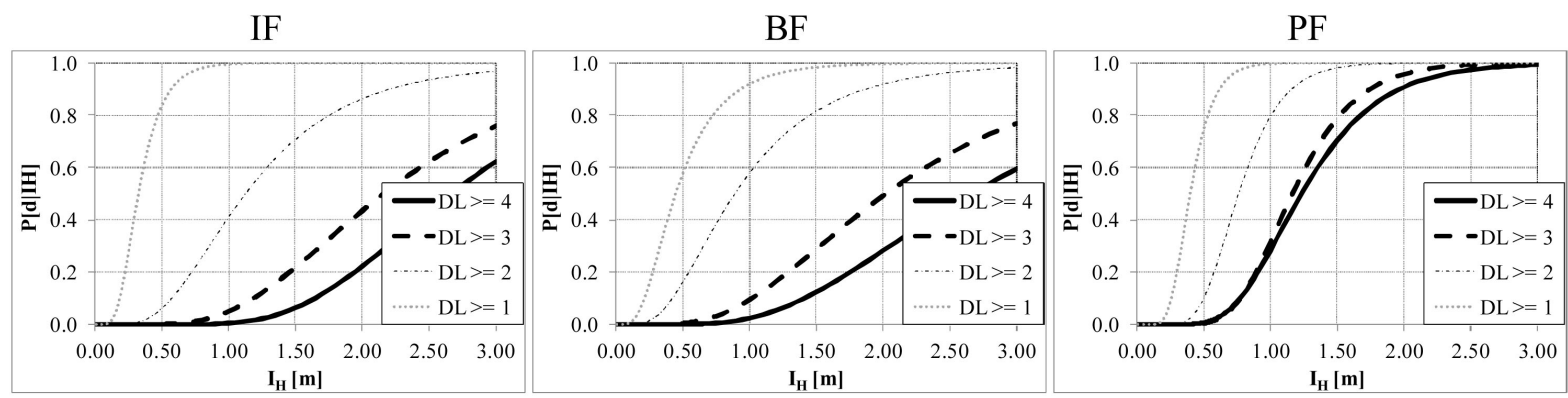

Figure 13. Fragility curves: Pre-Code 4 storey IF, BF, PF.

IF

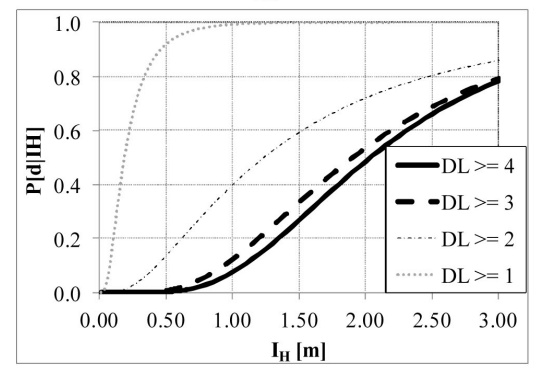

BF

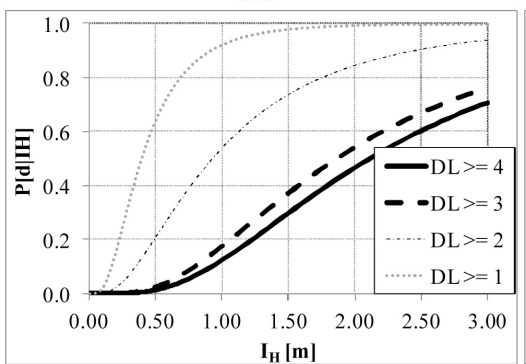

PF

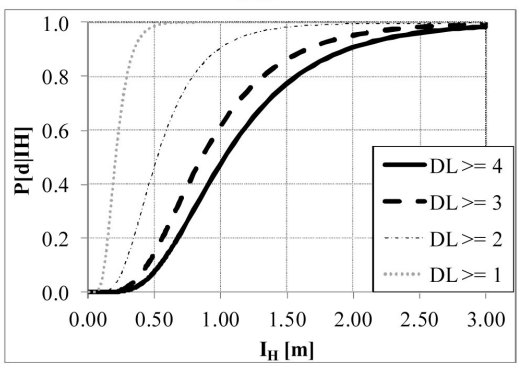

Figure 14. Fragility curves: Pre-Code 8 storey IF, BF, PF.

Each damage level has been quantitatively defined through limit values of local demand parameters on structural members. Subsequently, the correlation between local and global failure has been established. Then, the proposed method has used IDR as global performance indicator; it is dependent on parameters governing the seismic structural performance levels.

A new relationship among structural performance, damage levels and IDR for each studied type has been introduced, which is calibrated considering the damage levels described in EMS98 [33].

Finally, FCs have been obtained considering Housner intensity, but other seismic intensity parameters could be easily used in order to compare this study with others studies; FCs can be easily defined considering different seismic intensity measures. Considering the relationship to convert $I_{H}$ into EMS98 [33] intensity (see Chiauzzi et al. [5]), FCs have been used in large-scale loss scenarios.

These are the specialties of this study which puts it in a different path when compared to the other published works.

It is to be noted that FCs have been defined considering some characteristics that could be easily surveyed [6] or obtained from the available information (for example, census survey, ISTAT [38]). Thus, the proposed procedure is applicable in large-scale vulnerability studies. Moreover, FCs have been obtained considering the Housner intensity, but other seismic intensity parameters could be easily used in order to compare this study with others studies. Considering the relationship to convert $I_{H}$ into EMS98 intensity, FCs has been used in 
large-scale loss scenarios [8].

In seismic risk mitigation policies, FCs must be defined considering the repair/retrofitting costs. FCs could be defined considering an economic point of view, which requires that the higher level of economic losses be adequately captured. For example, in Dolce et al. 2006, a methodology for the evaluation of economic losses has been presented. This methodology is based on the repair cost conditional upon the suffered damage level and the building type. An economic damage index $C_{r, r}$ (relative repair cost) was evaluated, equal to the ratio of the cost of repair to the cost of replacing the building.

It is concluded that defining an accurate tool for seismic reduction strategies is essential for accurate structural performance analysis. The consequent procedure can be applied with a good approximation at databases of European RC buildings. This matter has great importance. Moreover, the results of analytically simulated analyses are relevant to supplement other procedures based on empirical formulation that generally has been calibrated on observed behaviour and damage data surveyed after earthquakes.

\section{References}

[1] Vona, M., Harabaglia, P. and Murgante, B., (2013) Resilient Cities, Lesson from Recent Italian Earthquakes, Vienna Congress on Recent Advances in Earthquake Engineering and Structural Dynamics 2013 (VEESD 2013), 28-30 August 2013, Vienna, Austria. Proceedings, In: Adam, C., Heuer, R., Lenhardt, W. and Schranz, C., Eds., ISBN-Nummer, 978-3-902749-04-8.

[2] Yakut, A. (2004) Reinforced Concrete Frame Construction. World Housing Encyclopedia—Summary Publication.

[3] Dolce, M., Kappos, A.J., Masi, A., Penelis, G. and Vona, M. (2006) Vulnerability Assessment and Earthquake Scenarios of the Building Stock of Potenza (Southern Italy) Using the Italian and Greek Methodologies. Engineering Structures, 28, 357-371. http://dx.doi.org/10.1016/j.engstruct.2005.08.009

[4] Goretti, A., Bramerini, F., Di Pasquale, G., Dolce, M., Lagomarsino, S., Parodi, S., Iervolino, I., Verderame, G.M., Bernardini, A., Penna, A., Rota, M., Masi, A. and Vona, M. (2008) The Italian Contribution to the USGS PAGER Project. Proc. of 14th World Conference on Earthquake Engineering, Beijing, 2008.

[5] Chiauzzi, L., Masi, A., Mucciarelli, M., Vona, M., Pacor, F., Cultrera, G., Gallovič, F. and Emolo, A. (2012) Building Damage Scenarios Based on Exploitation of Housner Intensity Derived from Finite Faults Ground Motion Simulations. Bulletin of Earthquake Engineering, 10, 517-545. http://dx.doi.org/10.1007/s10518-011-9309-8

[6] Masi, A., Chiauzzi, L., Samela, C., Tosco, L. and Vona, M. (2014) Survey of Dwelling Buildings for Seismic Loss Assessment at Urban Scale, the Case Study of 18 Villages in Val d'AgrI, Italy. Environmental Engineering and Management Journal, in press.

[7] Borzi, B., Vona, M., Masi, A., Pinho, R. and Pola, D. (2013) Seismic Demand Estimation of RC Frame Buildings Based on Simplified and Nonlinear Dynamic Analyses. Earthquakes and Structures, 4, 157-179. http://dx.doi.org/10.1007/s10518-011-9309-8

[8] Puglia, R., Vona, M., Klin, P., Ladina, C., Masi, A., Priolo, E. and Silvestri, F., (2013) Analysis of Site Response and Building Damage Distribution Due to the 31 October 2002 Earthquake at San Giuliano di Puglia (Italy). Earthquake Spectra, 29, 497-526. http://dx.doi.org/10.1193/1.4000134

[9] Masi, A. and Vona, M., (2012) Vulnerability Assessment of Gravity-Load Designed RC Buildings, Evaluation of Seismic Capacity through Non Linear Dynamic Analyses. Engineering Structures, 45, 257-269. http://dx.doi.org/10.1016/j.engstruct.2012.06.043

[10] Padgett, J.E. and DesRoches, R. (2006) Bridge Damage-Functionality Using Expert Opinion Survey. 8th National Conference on Earthquake Engineering, Earthquake Engineering Research Institute, San Francisco.

[11] Rossetto, T. and Elnashai, A. (2003) Derivation of Vulnerability Functions for European-Type RC Structures Based on Observational Data. Engineering Structures, 25, 1241-1263. http://dx.doi.org/10.1016/S0141-0296(03)00060-9

[12] Huang, Q., Gardoni, P. and Hurlebaus, S. (2009) Probabilistic Capacity Models and Fragility Estimates for Reinforced Concrete Columns Incorporating NDT Data. Journal of Engineering Mechanics, 135, 1384-1392. http://dx.doi.org/10.1061/(ASCE)0733-9399(2009)135:12(1384)

[13] Banerjee, S. and Shinozuka, M. (2008) Experimental Verification of Bridge Seismic Damage States Quantified by Calibrating Analytical Models with Empirical Field Data. Earthquake Engineering and Engineering Vibration, 7, 383-393. http://dx.doi.org/10.1007/s11803-008-1010-9

[14] Dumova-Jovanoska, E. (2000) Fragility Curves for Reinforced Concrete Structures in Skopje (Macedonia) Region. Soil Dynamics and Earthquake Engineering, 19, 455-466. http://dx.doi.org/10.1016/S0267-7261(00)00017-8

[15] Cornell, C.A. and Krawinkler, H. (2000) Progress and Challenges in Seismic Performance Assessment. PEER Center 
News, 3, 1-3.

[16] Kwon, O. and Elnashai, A. (2006) The Effect of Material and Ground Motion Uncertainty on the Seismic Vulnerability Curves of RC Structure. Engineering Structures, 28, 289-303. http://dx.doi.org/10.1016/j.engstruct.2005.07.010

[17] Kappos, A.J., Panagopoulos, G., Panagiotopoulos, C. and Penelis, G. (2006) A Hybrid Method for the Vulnerability Assessment of R/C and URM Buildings. Bulletin of Earthquake Engineering, 4, 391-413. http://dx.doi.org/10.1007/s10518-006-9023-0

[18] Lagomarsino, S. and Giovinazzi, S. (2006) Macroseismic and Mechanical Models for the Vulnerability and Damage Assessment of Current Buildings. Bulletin of Earthquake Engineering, 4, 415-443. http://dx.doi.org/10.1007/s10518-006-9024-z

[19] Polese, M., Verderame, G.M., Mariniello, C., Iervolino, I. and Manfredi, G. (2008) Vulnerability Analysis for Gravity Load Designed RC Buildings in Naples-Italy. Journal of Earthquake Engineering, 12, 234-245. http://dx.doi.org/10.1080/13632460802014147

[20] Erberik, M.A. (2008) Fragility-Based Assessment of Typical Mid-Rise and Low-Rise RC Buildings in Turkey. Engineering Structures, 30, 1360-1374. http://dx.doi.org/10.1016/j.engstruct.2007.07.016

[21] Ramirez, C. and Miranda, E. (2009) Building-Specific Loss Estimation Methods \& Tools for Simplified PerformanceBased Earthquake Engineering. John A. Blume Earthquake Engineering Research Center, Stanford University, Report No. 171, Stanford.

[22] Celik, O.C. and Ellingwood, B.R. (2009) Seismic Risk Assessment of Gravity Load Designed Reinforced Concrete Frames Subjected to Mid-America Ground Motions. Journal of Structural Engineering, 135, 414-424. http://dx.doi.org/10.1061/(ASCE)0733-9445(2009)135:4(414)

[23] Celik, O.C. and Ellingwood, B.R. (2010) Seismic Fragilities for Non-Ductile Reinforced Concrete Frames-Role of Aleatoric and Epistemic Uncertainties. Structural Safety, 32, 1-12. http://dx.doi.org/10.1016/j.strusafe.2009.04.003

[24] Kappos, A.J. and Panagopoulos, G. (2010) Fragility Curves for Reinforced Concrete Buildings in Greece. Structure and Infrastructure Engineering: Maintenance, Management, Life-Cycle Design and Performance, 6, 39-53. http://dx.doi.org/10.1080/15732470802663771

[25] El Howary, H.A. and Mehanny, S.S.F. (2011) Seismic Vulnerability Evaluation of RC Moment Frame Buildings in Moderate Seismic Zones. Earthquake Engineering and Structural Dynamics, 40, 215-235. http://dx.doi.org/10.1002/eqe.1016

[26] Javanpour, M. (2012) Assessment of the Seismic Behaviour of the Reinforced Concrete Structures Based on the Probabilities, Implementing Fragility Curves. Journal of Civil Engineering and Science, 1, 59-64.

[27] Shoraka, M.B., Yang, T.Y. and Elwood, K.J. (2013) Seismic Loss Estimation of Non-Ductile Reinforced Concrete Buildings. Earthquake Engineering \& Structural Dynamics, 42, 297-310. http://dx.doi.org/10.1002/eqe.2213

[28] Spence, R. and Le Brun, B. (Guest Editors) (2006) Preface. Bulletin of Earthquake Engineering, 4, 319-463. http://dx.doi.org/10.1007/s10518-006-9019-9

[29] Federal Emergency Management Agency (FEMA) (2009) FEMA P695 Recommended Methodology for Quantification of Building System Performance and Response Parameters. Project ATC-63, Prepared by the Applied Technology Council, Redwood City.

[30] Masi, A., Vona, M. and Mucciarelli, M. (2011) Selection of Natural and Synthetic Accelerograms for Seismic Vulnerability Studies on RC Frames. Journal of Structural Engineering, 137, 367-378. http://dx.doi.org/10.1061/(ASCE)ST.1943-541X.0000209

[31] Vargas, Y.F., Pujades, L.G., Barbat, A.H. and Hurtado, J.E. (2013) Capacity, Fragility and Damage in Reinforced Concrete Buildings: A Probabilistic Approach. Bulletin of Earthquake Engineering, 11, 2007-2032. http://dx.doi.org/10.1007/s10518-013-9468-x

[32] Seismic Rehabilitation of Existing Buildings (2007) ASCE STANDARD ASCE/SEI 41-06. American Society of Civil Engineers.

[33] Grünthal, G. (Ed.) (1998) European Macroseismic Scale 1998 (EMS-98) European Seismological Commission, sub commission on Engineering Seismology, Working Group Macroseismic Scales. Conseil de l'Europe, Cahiers du Centre Européen de Géodynamique et de Séismologie, Vol. 15, Luxembourg.

[34] Vona, M. (2013) Use of Fragility Curves in Emergency Management and Seismic Risk Mitigation. Vienna Congress on Recent Advances in Earthquake Engineering and Structural Dynamics 2013 (VEESD 2013), Adam, C., Heuer, R., Lenhardt, W. and Schranz, C., Eds., 28-30 August 2013, Vienna.

[35] Masi, A. and Vona, M. (2010) Experimental and Numerical Evaluation of the Fundamental Period of Undamaged and Damaged RC Framed Buildings. Bulletin of Earthquake Engineering, 8, 643-656. http://dx.doi.org/10.1007/s10518-009-9136-3 
[36] Ditommaso, R., Vona, M., Gallipoli, M.R. and Mucciarelli, M. (2013) Evaluation and Considerations about Fundamental Periods of Damaged Reinforced Concrete Buildings. Natural Hazard and Earth System Science, 13, 1903-1912. http://dx.doi.org/10.5194/nhess-13-1903-2013

[37] Gallipoli, M.R., Mucciarelli, M. and Vona, M. (2009) Empirical Estimate of Fundamental Frequencies and Relevant Damping for Italian Building. Earthquake Engineering and Structural Dynamics, 38, 973-988. http://dx.doi.org/10.1002/eqe.878

[38] ISTAT (2011) XV Censimento Generale Della Popolazione e Delle Abitazioni 2011. http://www.istat.it/

[39] Park, Y.J., Reinhorn, A.M. and Kunnath, S.K. (1987) IDARC, Inelastic Damage Analysis of Frame Shear-Wall Structures. Technical Report NCEER 87-0008, Buffalo.

[40] Valles, R.E., Reinhorn, A.M., Kunnath, S.K., Li, C. and Madan, A. (1996) Idarc 2d Version 4.0, a Program for the Inelastic Damage Analysis of Buildings. Technical Report NCEER 96-0010, Buffalo.

[41] Nanos, N. and Elenas, A. (2006) Seismic Duration Effects on the Vulnerability of Buildings. Proceedings of 1st European Conference on Earthquake Engineering and Seismology, Geneva, 3-8 September 2006.

[42] Buratti, N., Stafford, P. and Bommer, J. (2011) Earthquake Accelerogram Selection and Scaling Procedures for Estimating the Distribution of Drift Response. Journal of Structural Engineering, 137, 345-357. http://dx.doi.org/10.1061/(ASCE)ST.1943-541X.0000217

[43] Ambraseys, N., Smit, P., Douglas, J., Margaris, B., Sigbjornsson, R., Olafsson, S., Suhadolc, P. and Costa, G. (2004) Internet-Site for European Strong-Motion Data. Bollettino di Geofisica Teorica ed Applicata, 45, 113-129.

[44] Priestley, M.J.N., Calvi, G.M. and Kowalsky, M.J. (2007) Displacement-Based Seismic Design of Structures. IUSS Press, Pavia.

[45] NTC 2008) Norme Tecniche per le Costruzioni. Decreto del Ministero delle infrastrutture, Supplemento Ordinario n.30 alla Gazzetta Ufficiale della Repubblica italiana, 29, 4/02/2008, Italy. (in Italian)

[46] CEN (2005) EN 1998-3-1-4 Eurocode 8, Design of Structures for Earthquake Resistance, Part 3, Assessment and Retrofitting of Buildings. European Committee for Standardization. 